See Article page XXX.

\section{Commentary: The holy grail of aortic surgery}

\author{
Luca Weltert, $\mathrm{MD}, \mathrm{PhD},{ }^{\mathrm{a}}$ and \\ Michele Di Mauro, $\mathrm{MD}, \mathrm{PhD}^{\mathrm{b}}$
}

Aortic dissection is the ultimate problem of heart surgery. Despite all efforts and technology, mortality remains high, and operations often fall into the "heroic" zone of the spectrum. Finding a simple and effective clue to cast some light on the specific probability of an individual for developing aortic dissection and, consequently, developing a tailored indication for elective replacement of the ascending aorta with a 10-fold decrease in overall risk remains the holy grail of aortic surgery.

Currently, two parallel paths are being explored: anatomic and blood markers. The latter aims at finding some traceable blood molecule that is present in individuals who develop dissection and absent in those who do not. ${ }^{1}$ The anatomic path is particularly appealing for cardiac surgeons, who are keen on demonstrating their proficiency in eyeballing lengths, curves, arches, and other geometric facts and figures.

In this issue of the Journal, Salmasi and colleagues ${ }^{2}$ propose to identify a simple angular parameter to rule out the probability of incurring aortic dissection and show evidence, by means of cinematic assessment of shear stress via finite-element modeling and time-dependent equations, of its usefulness in assessing the impact of the bloodstream on the aortic wall.

The use of finite elements comes from the aerospace industry and involves dividing objects into reticular conglomerates of simple shapes, such as triangles, to evaluate

\footnotetext{
From the ${ }^{\mathrm{a}}$ Department of Cardiac Surgery, European Hospital, Rome, Italy and ${ }^{\mathrm{b}} \mathrm{Car}-$ dio-Thoracic Surgery Unit, Heart and Vascular Centre, Maastricht University Medical Centre, Cardiovascular Research Institute Maastricht, Maastricht, The Netherlands.

Disclosures: The authors reported no conflicts of interest.

The Journal policy requires editors and reviewers to disclose conflicts of interest and to decline handling or reviewing manuscripts for which they may have a conflict of interest. The editors and reviewers of this article have no conflicts of interest.

Received for publication June 4, 2021; revisions received June 4, 2021; accepted for publication June 4, 2021

Address for reprints: Michele Di Mauro, MD, PhD, Cardio-Thoracic Surgery Unit, Heart and Vascular Centre, Maastricht University Medical Centre (MUMC), P Debyelaan 25, 6202 AZ, Maastricht, The Netherlands (E-mail: mdimauro1973@ gmail.com).

J Thorac Cardiovasc Surg 2021; $\mathbf{\square}: 1-2$

$0022-5223 / \$ 36.00$

Copyright (c) 2021 Published by Elsevier Inc. on behalf of The American Association for Thoracic Surgery

https://doi.org/10.1016/j.jtcvs.2021.06.010
}

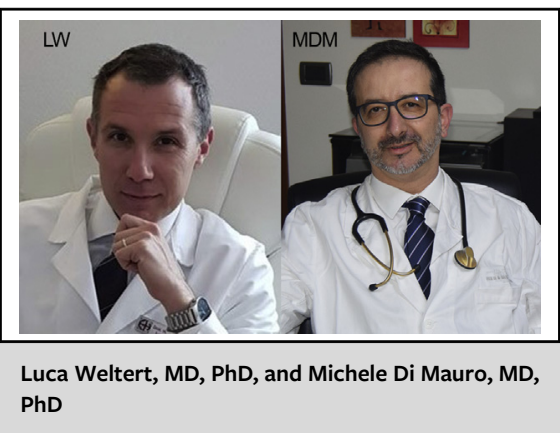

CENTRAL MESSAGE

Salmasi and colleagues propose

to identify a simple angular

parameter to rule out the prob-

ability of incurring into aortic

dissection, and shows evidence

by means of cinematic assess-

ment of shear stress, via finite

elements modeling.

numerically the impact of a vector on each spot using very complex sums of very simple basic geometric properties. In cardiovascular surgery, the use of this kind of analysis has its roots in the 1990s, evolving concomitantly with the increasing availability of raw calculation power.

The latest addition to the quiver of the "in silico" predicting tools is 4-dimensional flow analysis, which adds one more dimension to the tridimensional space: that is, time. By tracing particles in fluid over time, a reasonable approximation of flow pattern, incidence on vessel walls, and thus ultimately shear stress can be obtained, with interesting implications. ${ }^{4}$

The study by Salmasi and colleagues provides an elegant demonstration of how multiple sophisticated techniques can be used together to produce a beautifully simple prediction index. The data are solid, and the images are captivating. All in all, the article hints at the future to come, when tailored individual predictions will be readily available to the average patient in a matter of minutes, hopefully saving surgeons many nights fighting with aortic dissection.

\section{References}

1. Della Corte A, Michelena HI, Citarella A, Votta E, Piatti F, Lo Presti F, et al. Risk stratification in bicuspid aortic valve aortopathy: emerging evidence and future perspectives. Curr Probl Cardiol. 2021;46:100428.

2. Salmasi MY, Pirola S, Mahuttanatan S, Fisichella SM, Sengupta S, Jarral OA, et al Geometry and flow in ascending aortic aneurysms are influenced by left ventricular outflow tract orientation. J Thorac Cardiovasc Surg. 2021 [In press]. 
3. Grande-Allen KJ, Cochran RP, Reinhall PG, Kunzelman KS. Mechanisms of aortic valve incompetence: finite-element modeling of Marfan syndrome. $J$ Thorac Cardiovasc Surg. 2001;122:946-54.
4. Galea N, Piatti F, Lau C, Sturla F, Weltert L, Carbone I, et al; Cornell International Consortium for Aortic Surgery (CICAS). 4D flow characterization of aortic blood flow after valve sparing root reimplantation procedure. J Vis Surg. 2018;9:95. 